\title{
(1)
}

\begin{tabular}{|l||c|c|}
\hline \hline Received 25.05.2021 & & JOTS \\
$5 / 2$ \\
\hline \hline Accepted 13.06.2021 & Review & $2021: 440-445$ \\
\hline \hline Published 24.07.2021 & & \\
\hline
\end{tabular}

\section{Erdem, M. D. \& Demirci, Ü. Ö. Köktürkçe, Ankara: Pruva Yayınlar1, 2019, ss. 662, ISBN: 978-605-80397-0-4}

\author{
Aysun SOYER ${ }^{*}$ \\ Düzce / T urkey \\ E-mail: aysunsoyer.as@gmail.com
}

Son yıllarda Eski Türkçeyi öğretme amacıyla yazılmış ders kitabı formatındaki kitaplardan birisi de üzerinde duracağım bu eserdir. Eser şu bölümlerden meydana gelmiştir:

İçindekiler Dizini (7-26) alfabetik sıraya göre hazırlanmış olup ilgili kelimenin ve gramer konusunun sayfa numaraları gösterilmiştir. Ön Söz (27-28) bölümünde, okurlara kitap tasarlanırken ne tür yaklaşımların benimsendiği aktarılmıştır. Giriş (29-73) bölümü Türkçenin dünya dilleri arasındaki yeri, Ural-Altay dilleri nazariyesi, Altay dilleri nazariyesi ile başlamaktadır. Ardından Türkçenin tarihi gelişimi: Proto-Türkçe: (Ön Türkçe), Eski Türkçe: (VIII-X. yy.), Orta Türkçe Dönemi: (XI-XII. yy.), Karahanlı lehçesi, Yeni Türkçe Dönemi: (XIII. yüzyılda başlar), Batı Türkçesi, Çağdaş lehçeler gibi alt başlıklarla anlatılmıştır. Köktürklerin kökeni, I. ve II. Köktürk Devletleri, Köktürk Devletleri’nden kalan eserler ve bu eserler üzerine yapılan çalışmalar, Köktürk yazısının kökeni ile ilgili görüşler ele alınmaktadır

Bu başlıkların ardından Eski Türkçe üzerine yazılmış dilbilgisi kitapları ve etimoloji sözlükleri hakkında bilgilere yer verilmiştir.

Köktürk yazısı ve karşılı̆̆ı, Kısaltmalar, İşaretler ve Bibliyografya verilerek giriş bölümü tamamlanmıştır. Bibliyografya bölümünde çalışmada kullanılan 129 kaynak APA sistemi kullanılarak belirtilmiştir.

\footnotetext{
ORCID ID: 0000-0002-9638-8315.
} 
Eserin ikinci bölümünde (75-623) Köl Tegin, Bilge Kağan, Tuñukuk yazıtlarının tamamı incelenmiştir. Bu yazıtlara ait satırların her biri orijinal metni, transliterasyonu (harfçevrimi), transkripsiyonu (yazıçevrimi) ve Türkiye Türkçesine aktarımı yapıldıktan sonra okuma farklılığı gözlenen cümlelerin bugüne kadar yazıtları neşredenler tarafından nasıl okunduğu ve anlamlandırıldığı sıralanmıştır. Metinler Türkiye Türkçesine aktarılırken satır altı karşlıkları sunulmuştur. Kitaptaki transkripsiyon ve tercüme, genellikle Erhan Aydın'ın Orhon Yazıtları adlı eserinden alınmış; bazı satırların transkripsiyonunda ve tercümesinde Ercilasun, Tekin, Ergin ve yazıtları neşreden diğer Türkologların transkripsiyon ve çevirileri de kullanılmıştır. Aydın'ın Orhon Yazıtları adlı eserinden alınan transkripsiyon ve tercümeler hariç diğer Türkologlardan tercih edilen transkripsiyon ve tercümenin hangi eserden alındığı dipnotta belirtilmiştir.

Bir örnek:

\section{Orijinal Metin}

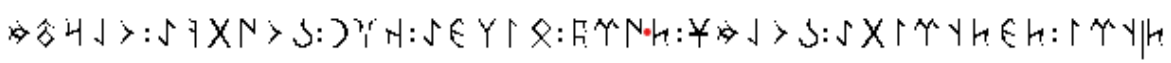

\section{Transliterasyon}

tyri tg tyride bolmş türük bilge kg்n boödke olrtm

\section{Transkripsiyon}

$\mathrm{t}(\mathrm{e})$ yri $\mathrm{t}(\mathrm{e}) \mathrm{g} \mathrm{t}(\mathrm{e})$ yride bolm(1)ş türük bilge $\mathrm{k}(\mathrm{a}) \mathrm{g}(\mathrm{a}) \mathrm{n}$ bo ödke ol(u)rt(u)m.

\section{Çeviri}

(Ben) Tenriteg Tenride Bolmış Türk Bilge Kağan'(ım) bu zamanda tahta oturdum.

tegriteg tegride bolmış "Bu ibare Thomsen tarafından ilk önce "Ben Tanrı gibi Tanrı'ya benzeyen" biçiminde tercüme edilmiştir. Fakat daha sonra Thomsen tarafından "Tanrı gibi gökte olmuş" olarak değiştirilmiştir”. Radloff da Thomsen'e yakın çeviri ileri sürmüştür, Malov da bu görüşü benimsemiştir. Berta “(Ben) Tengri gibi gökte (Tengri'den) doğmuş Türk Bilge Kağan bu zamanda hüküm sürdüm”. Ercilasun: “\{Ben\} semavi Tanrı'dan olmuş Türk Bilge Kağan\{ım\}”; Orkun: "Göğe benzer gökte (mevcut) olmuş Türk Bilge hakan bu zamanda (iktidar 


\section{0}

mevkiine) oturdum"; Ergin: “Tanrı gibi gökte olmuş Türk Bilge Kağanı”; Tekin: “(Ben), Tanrı gibi (ve) Tanrı'dan olmuş Türk Bilge Hakan”.

Tekin, bu cümlede iki niteleme grubu karşısında olduğumuza dikkat çekerek, birinci ibarenin tegri teg, ikinci ibarenin ise tenride bolmış olduğunu, birinci ibarenin 'Tanrı gibi, Tanrıca, ilâhi', ikinci ibarenin 'Tanrı'dan olmuş' biçiminde anlaşılması gerektiğini belirtir. Bu görüşüne kanıt olarak da Çin İmparatorlarının 天子 tianzi 'göğün oğlu, Tanrı'nın oğlu' (Eski Türkçe metinlerde ténsi biçiminde geçer) unvanını taşıdıklarını belirtir. Bu şekilde yazıtların her bir satırının incelenmesi öğrencilerin yazıtları öğrenebilmesi ve anlaması için önemli bir kolaylık sağlamıştır.

$\mathrm{Bu}$ şekilde yazıtların her bir satırının incelenmesi öğrencilerin yazıtları öğrenebilmesi ve anlaması için önemli bir kolaylık sağlamıştır. Okuyucu bu şekilde yazıtlar üzerine çalışma yapan Türkologları ve onların görüşünü de bir arada görme imkânına sahip olmuştur.

Daha sonra kelimelerin kök-ek ayrımları yapılarak kelimelerin etimolojik açıklamalarına yer verilmiştir. Bu açıklamalarla birlikte kelimelerle eklerin tarihî ve çağdaş lehçelerdeki gelişimleri de gösterilmiştir. Sözcüklerin etimolojisi için Clauson, Nadalyayev et al., Starostin et al., Räsänen, Doerfer, Radloff, Eren, Gülensoy vb. yazarların çalışmaları temel alınmıştır. Sözcüklerin açıklamalarında; Şirin'in Kül Tigin Yazıtı Notları, Tekin'in Orhon Yazıtları ve Tuñukuk Yazıtı adlı eserlerindeki notlar, Ercilasun'un Türk Kağanlığı ve Türk Bengü Taşları adlı eserindeki notlardan yapılmıştır.

\section{Kelime Örneği}

iniygünüm : ini $(y)+{ }^{\mathrm{iK}}$ gün+ ${ }^{\mathrm{iiYE}}(\ddot{u}) \mathrm{m}^{1 \mathrm{TK} i E}$

Kökeni: ini: > iniy

Anlamı: 'erkek kardeşlerim'

Thomsen, kelimeyi ini 'erkek kardeş’ kelimesine $\{+g U n\}$ isimden isim yapan yapım ekinin gelip kaynaşmasından oluşmuş türemiş isim saymaktadır. Tekin, ini-yegün biçiminde iki kelimeden oluşan bir şekil olarak kabul etmiş ve buna dayanak olarak da Moğolcadaki degüü 'erkek kardeş' kelimesini göstermiştir; ancak gerek tarihî lehçelerde gerekse çağdaş lehçelerde yegün kelimesine rastlanmamasından dolayı Tekin bu görüşünden vazgeçer ve Thomsen'in önerisine katılır. Kelimede türeyen /y/ konsonantını da ini: kelimesindeki uzun /i:/ vokali ile açıklamaktadır. Şirin ini kelimesi ile ilgili şu bilgileri vermiştir: “Kaşgarlı DLT'de adamın erkek kardeşi adamdan 
küçükse ini, büyükse eke diye söylenir, bir adamın kız kardeşi kendisinden küçükse sinil büyükse eke denir". Yong-Sŏng Li, şu açıklamayı yapmıştır: 'küçük kardeş' anlamındaki bu sözcük ilk olarak Orhon Yazıtlarında ini biçiminde geçmektedir: inim köl tégin özi ança kergek boltı (KT D 30), Uygur metinlerinde ini 'küçük erkek kardeş’ biçiminde geçmektedir: ini içi tüzülti “erkek kardeşler anlaştılar” (TT I 12). Bu sözcüğün tarihî ve çağdaş lehçelerdeki seyrini de Yong-Sŏng Li şöyle vermiştir: ini 'erkek kardeş' (KB 146), ini 'erkek kardeş, kayın birader' (DLT I 93, III 7), ini 'erkek torun' (KW 107), 'gen' (HŞ), inek 'küçük erkek kardeş' (PC 138, kelimede türeyen /k/ aslında küçültme ekidir), ineke 'küçük erkek kardeş' (PC 138, \{+ke\} aslında küçültme ekidir), çağdaş lehçelerde: TT. eni 'küçük erkek kardeş' (DS 1756), yine Türkiye lehçesinde bu kelimeye getirilen $\{+k\}$ isimden isim küçültme eki ile yapılmış enik 'köpek yavrusu' kelimesi de bulunmaktadır. Trk. ini 'küçük erkek kardeş'; Sal. ine 'küçük erkek kardeş’; Yuy. ini, inä 'küçük erkek kardeş’; Özb. ini, iné 'küçük erkek kardeş'; Kumk. ini 'küçük erkek kardeş'; Nog. ini 'küçük erkek kardeş’; Kzk. ini 'küçük erkek kardeş’; Krkp. ini 'küçük erkek kardeş’; inň 'küçük erkek kardeş’ Tat. ǐn 'küçük erkek kardeş’; Bşk. ǐň` ‘küçük erkek kardeş’; Baraba äni 'küçük erkek kardeş’; Kırg. ini 'küçük erkek kardeş'; Alt. iyin 'küçük erkek kardeş'; Suy. ini, ını, eni, ene, ınıy 'küçük erkek kardeş'; Yak. ini 'küçük erkek kardeş; baba tarafından yaşça küçük erkek akraba'; Dolg. ini ‘küçük erkek kardeş’; Hal. ini 'küçük erkek kardeş’ (s. 109110).

Yazıtlarda yer alan tüm kelimelerin detaylı şekilde etimolojilerinin yapılması, kelimeler üzerine Türkologlar tarafından yapılan açıklama ve yorumlara yer verilmesi tüm bilgilerin tek bir kaynakta toplandı̆̆ını göstermektedir. Kelimelerin Tarihî ve Çağdaş lehçelerindeki durumunun verilmesi karşılaştırma yapabilme imkânı sağlamıştır.

\section{Dil bilgisi Örneği \\ Datif (Yönelme) Hâl Eki}

Eski Türkçede: Datif hâl eki, $\{+\mathrm{kA}\},\{+\mathrm{A}\}$ biçiminde bulunmaktadır: taşka, ıgaçka, ewke, adaka, yaşıma, bodunuma. Yine Eski Türkçede ve tarihî lehçelerde $\{+\mathrm{kA}\}$ datif hâl eki, üçüncü şahıs iyelik eki ve pronominal /n/'den sonra geldiği zaman, pronominal n ile kaynaşarak $\{+y A\}$ biçimine dönüşür, Tekin, bunu "bu biçimin hiç kuşkusuz, daha eski bir $(+n+g A)$ ya da $(+n+k A)$ biçiminden gelmiş olabileceğini belirtir”. Örnekler: sabina, oglina, batsıkıja, agısina vs.

Karahanlı Lehçesinde: $\{+\mathrm{kA}\},\{+\mathrm{gA}\},\{+\mathrm{A}\}$ biçiminde görülür. Konsonant benzeşmesi nedeniyle sedalı konsonanttan sonra $\{+\mathrm{kA}\}$, sedasız konsonanttan sonra $\{+\mathrm{gA}\}$ biçiminde görülür. Ayrıca Eski Türkçedeki gibi az sayıda kelimede $\{+A\}$ biçimi de 


\section{J(৫)}

görülmektedir: bagka (KB 1808), kökke (KB 1002), eligge (DLT II 123, 127), ayaga (DLT III 172), bege (KB 5118).

Harezm Lehçesinde: Karahanlı lehçesindeki gibi $\{+\mathrm{kA}\},\{+\mathrm{gA}\},\{+\mathrm{A}\}$ biçiminde görülür. Konsonant benzeşmesi nedeniyle sedalı konsonanttan sonra $\{+\mathrm{kA}\}$, sedasız konsonanttan sonra \{+gA\} biçiminde görülür. Ayrıca Eski Türkçedeki gibi az sayıda kelimede $\{+\mathrm{A}\}$ biçimi de görülmektedir: aklımka (Kutb. 268), başga (Kutb. 598), evinge (KE 34/1), özine (Kutb. 2463).

Kıpçak Lehçesinde: Bu dönemde de tıpkı Karahanlı ve Harezm lehçelerinde olduğu gibi $\{+\mathrm{kA}\},\{+\mathrm{gA}\},\{+\mathrm{A}\}$ biçiminde görülür: avga (EH 145), kulga (TZ 78a), evge (CC 123, 5), tamukka (CC 125, 5), yükke (CC 160, 19), üstüme (CC 45), artıma (TZ 74a 7).

Çağatay Lehçesinde: Çağatay lehçesinde de Karahanlı, Harezm ve Kıpçak lehçelerinde olduğu gibi $\{+\mathrm{kA}\},\{+\mathrm{gA}\},\{+\mathrm{A}\}$ biçiminde görülür: yolga, ayga, közge, çahka, kökke, tüşke, sözümize, kavluyuza.

Batı Türkçesinde: $B u$ dönemde umumiyetle $\{+A\}$ biçimindedir; ancak Eski Anadolu lehçesinin ilk dönemlerinde zaman zaman $\{+g A\}$ biçiminde de görülmektedir: içine, ölüye, evge, şehrine.

\section{Çağdaş Lehçelerde (s. 85-86)}

\begin{tabular}{||l||l||}
\hline \hline Az., Trkm. & $+A$ \\
\hline \hline $\begin{array}{l}\text { Tat., Bşk., Nog., Kzk., KKalp., } \\
\text { Krm., Tuv. }\end{array}$ & $+g A,+k A,+A$ \\
\hline \hline KBalk. & $+g A,+h a,+\eta A$ \\
\hline \hline Kum. & $+g A,+A,+g A r$ \\
\hline \hline Kırg., Alt. & $+g A,+k A,+A, g O,+k O,+O$ \\
\hline \hline Hak. & $+g A,+h a,+k e,+A$ \\
\hline \hline YUyg. & $+g A,+k A$ \\
\hline \hline$\ddot{O} z b .^{\text {Yakut }}$ & $+g e,+k A$ \\
\hline \hline Çuvaş & $+g A,+k A,+g O,+k O,+h A,+h O,+\eta A$, \\
$+\eta \eta O$ \\
\hline
\end{tabular}

Kitabın Eski Türkçe grameri niteliği taşımasının yanı sıra Tarihi ve Çağdaş lehçelerin gramer özeti niteliğini de taşıdı̆̆ı görülmektedir. Buna ek olarak kitap Türk dilini art zamanlı ve eş zamanlı tanıma fırsatı sağlamıştır.

Son bölümde Fin atlasından alınan Orijinal Metinler (Tıpkıbasımlar, 625661) verilmiştir.

Sonuç olarak söz konusu çalışma ciddi bir ön hazırlık evresinin yanında, geniş bir kaynakça taramasıyla meydana gelmiştir. Eski Türkçe dönemi üzerine 


\section{J(ఠ)}

çalışma yapacak olan araştırmacıların öncelikle yararlanabileceği bu eser Türk dilini art zamanlı ve eş zamanlı tanıma fırsatı sunmaktadır. Köktürkçe, Türk Dili ve Edebiyatı öğrencilerine Köktürkçe dönemini düşünme, anlama ve yorumlama imkânı veren bir başvuru kaynağı niteliği taşımaktadır. Bu kitap bundan sonra hazırlanacak ders kitapları için örnek teşkil edebilir. Kitabın yazarlarını tebrik ederim.

\section{Kaynakça}

Erdem, M. D. \& Demirci, Ü. Ö. (2019). Köktürkçe. Pruva Yayınları. 